\title{
Carbon-13 Nuclear Magnetic Resonance Spectroscopy of Polystyrene
}

\author{
S. Suparno, ${ }^{*}$ J. Lacoste, ${ }^{* *}$ S. RAynal, ${ }^{* * *}$ J. F. ReGnier, ${ }^{* * * *}$ \\ F. SCHUÉ, $* *, \dagger$ R. SEMPERE, ${ }^{* * * *}$ and J. SLEDZ** \\ *Institut de Technologie de Bandung, Indonesie. \\ **Laboratoire de Chimie Macromoléculaire, USTL, Place Bataillon, \\ 34060 Montpellier Cedex, France. \\ ***Centre de Recherches du Bouchet, Société Nationale des Poudres et Explosifs, \\ BP 2, 91710 Vert le Petit, France. \\ ****Laboratoire de Chimie Structurale, USTL, Place Bataillon, \\ 34060 Montpellier, France.
}

(Received May 9, 1980)

\begin{abstract}
Carbon-13 nuclear magnetic resonance configurational assignments are made for a free-radical polystyrene sample examined at $25.033 \mathrm{MHz}$ and $140^{\circ} \mathrm{C}$. The spectra of the aromatic $\mathrm{C}_{1}$ and methylene were examined. New assignments were established based strictly on a oneparameter Bernoullian fit that was in satisfactory agreement with the relative intensities of the peaks
\end{abstract} observed.

KEY WORDS Carbon-13 / Nuclear Magnetic Resonance / Polystyrene / Free
Radical/

Many studies have shown that carbon-13 nuclear magnetic resonance $\left({ }^{13} \mathrm{C}\right.$ NMR $)$ is a useful tool for detecting and measuring the distributions of stereochemical configurations that can occur in polymers. ${ }^{1-7}$ Monomer placement assignments (triad, tetrad, pentad, etc.) are generally made after observing a close conformity of a methylene or methine-intensity distribution with either Markov or Bernoullian statistics.

Stereochemical configuration in polystyrene has been the subject of many ${ }^{13} \mathrm{C}-\mathrm{NMR}$ investigations. $^{8-15}$

The spectrum of polystyrene was first measured by Bovey et al., ${ }^{8}$ revealing that the aromatic $\mathrm{C}_{1}$ spectrum is affected by the polymer stereochemistry. At about the same time, Inoue et al. ${ }^{10}$ showed that the $\mathrm{C}_{1}$ resonances observed in chloroform at $70^{\circ} \mathrm{C}$ split into three distinct groups, which were assigned to isotactic $(\mathrm{mm})$, heterotactic $(\mathrm{mr})$, and syndiotactic (rr) triads. Moreover, the expanded and refined $\mathrm{C}_{1}$ spectrum observed in $o$-dichlorobenzene at $160^{\circ} \mathrm{C}$ shows that the pentad resonances are partially resolved. Six pentad peaks have been

† To whom all correspondence should be addressed. resolved within ten possible pentads. Under the same conditions, the splitting of the methylenecarbon resonance is attributed to tetrad resonances: The spectrum observed at an elevated temperature is clearly resolved into five peaks. But Inoue et al. were unable to observe Bernoullian behaviour for a polystyrene obtained by a free-radical polymerization process.

Matsuzaki et al., ${ }^{9,11}$ reported the aromatic $\mathrm{C}_{1}$ carbon spectra of a radical polystyrene. Assuming that the polymerization proceeds according to the Bernoullian statistics, the three major absorptions of the aromatic $\mathrm{C}_{1}$ carbon were assigned in terms of pentad sequences.

The difference between the two assignments results from the interpretation of aromatic $\mathrm{C}_{1}$ carbon spectra. Inoue et al. assigned the three major absorptions of the $\mathrm{C}_{1}$ spectra measured in chloroform solution to isotactic, heterotactic, and syndiotactic triads, and derived all other assignments from this assignment. On the other hand, Matsuzaki et al. interpreted the three major absorptions of the $C_{1}$ spectra in terms of more than triads, i.e., pentads.

Randall ${ }^{12}$ examined a free-radical polystyrene ${ }^{13} \mathrm{C}$ 
NMR methylene-intensity distribution and obtained new assignments differing from these of Inoue that show one-parameter Bernoullian behaviour. The proportion of racemic diads $P_{\mathrm{r}}$ was 0.43 , different from the $P_{\mathrm{r}}$ values 0.71 and 0.69 observed respectively by Matsuzaki and Inoue.

For these reasons, we have made a more detailed study of a free-radical polystyrene. The spectra of the aromatic $\mathrm{C}_{1}$ and methylene were examined and assignments established.

\section{EXPERIMENTAL}

The ${ }^{13} \mathrm{C}$ NMR spectra were recorded at 25.033 $\mathrm{MHz}$ at approximately $150^{\circ} \mathrm{C}$ on a JEOL JNM PS100 spectrometer. The free-radical polystyrene samples were dissolved in ortho-dichlorobenzene and monobromoperdeuterobenzene was added to the mixture. Polystyrene spectra were accumulated with pulse spacings of 2.1 and $3.5 \mathrm{~s}$. The spectra were ${ }^{1} \mathrm{H}$ noise decoupled and obtained after accumulation of 7-25 thousand transients. Relative intensities were obtained through curve resolution, assuming a Lorentzian-peak shape.

\section{RESULTS AND DISCUSSION}

Analysis of the ${ }^{13} C$ NMR Spectra of the Aromatic $C_{1}$ Carbon of Polystyrenes Measured in oDichlorobenzene

In Figure 1 the aromatic $\mathrm{C}_{1}$ spectrum of a polystyrene prepared with a radical initiator is shown. It is assumed that the $\mathrm{C}_{1}$ absorptions are split into pentads which theoretically afford ten peaks (Figure 2). The peak at 146.64 is assigned to an $\mathrm{mmmm}$ pentad.

Assuming that the Bernoullian statistics hold in the polymerization of styrene, the proportion of each pentad was calculated. The $\mathrm{C}_{1}$ carbon spectra were assigned in terms of pentads in such a way that the calculated peak proportions agree best with the observed ones. The assignment shown in Table I was obtained as the best agreement with the observed peak proportions.

This assignment agrees well with the one established by Inoue (Table II) but does not conform to the one given by Matsuzaki (Table III). The proportion of racemic diads $P_{\mathrm{r}}$ is 0.72 and is close to the ones found by Matsuzaki and Inoue.

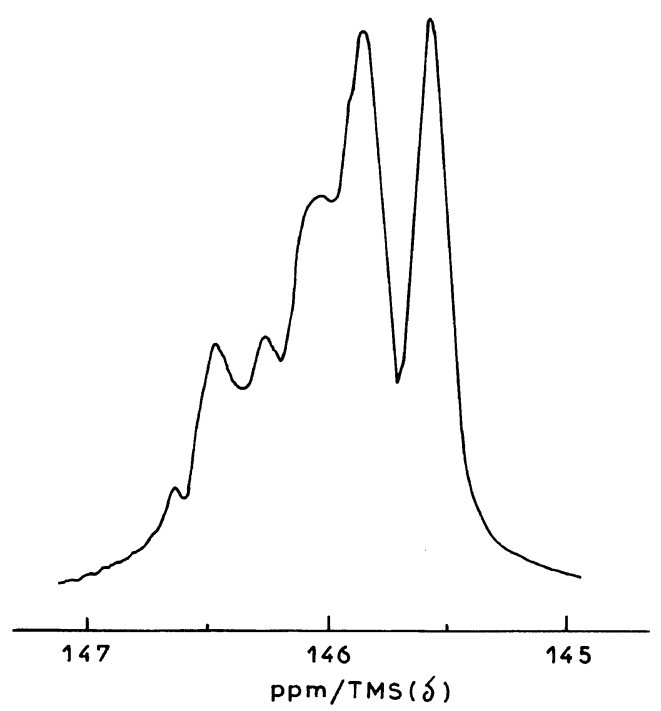

Figure 1. Observed ${ }^{13} \mathrm{C}$ NMR spectrum of the aromatic $\mathrm{C}_{1}$ carbon of a free-radical polystyrene.

Analyis of the ${ }^{13}$ C NMR Spectra of Methylene Carbon of Polystyrenes Measured in o-Dichlorobenzene

We examined a free-radical polystyrene ${ }^{13} \mathrm{C}$ NMR methylene-intensity distribution and obtained new assignments differing from those of Inoue and Randall, and showing one-parameter Bernoullian behaviour.

An ${ }^{1} \mathrm{H}$ noise-decoupled ${ }^{13} \mathrm{C}$ NMR spectrum is reproduced in Figure 3. Eight methylene resonances are present. The observation of eight resonances is in itself interesting since a ${ }^{13} \mathrm{C}$ NMR sensitivity to just tetrad sequences would have produced six resonances while a complete hexad sensitivity would have produce twenty resonances. A reasonable combination of tetrad and hexad resonances can possibly produce eight peaks but required an overlap among the various tetrad and hexad resonances (Figure 4). In the methylene region of the ${ }^{13} \mathrm{C}$ NMR spectrum of polystyrene, the $\mathrm{mmm}$ tetrad can be identified by a comparison with a polystyrene having a predominantly isotactic structure.

It is possible to make $\mathrm{CH}_{2}$ assignments in polystyrene after only one initial assignment if the methylene-intensity distribution conforms to a oneparameter statistical model.

The relative intensities of resonances are given in Table IV with eight calculated intensities using a $P_{\mathrm{m}}$ 

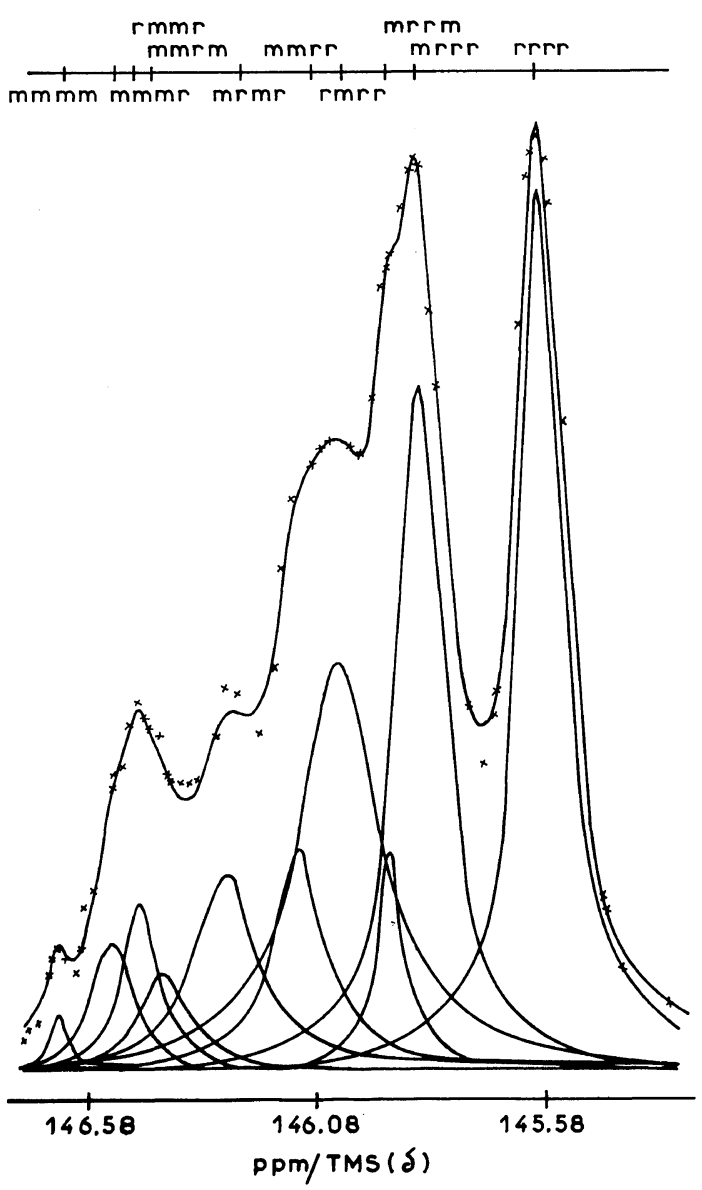

Figure 2. Composite ${ }^{13} \mathrm{C}$ NMR spectrum of the aromatic $\mathrm{C}_{1}$ carbon of a free-radical polystyrene.
Table I. Observed and calculated peak proportions of the ${ }^{13} \mathrm{C}$ NMR spectra of the aromatic $\mathrm{C}_{1}$ carbon of a free-radical polystyrene (our results) ${ }^{\mathrm{a}}$

\begin{tabular}{lcc}
\hline $\begin{array}{c}\text { Assignment } \\
\text { by pentads }\end{array}$ & Observed & $\begin{array}{c}\text { Calculated according } \\
\text { to a Bernoulian } \\
\text { statistics }\end{array}$ \\
\hline mmmm & 0.01 & 0.01 \\
$\mathrm{mmmr}$ & 0.03 & 0.03 \\
$\mathrm{rmmr}$ & 0.04 & 0.04 \\
$\mathrm{mmrm}$ & 0.03 & 0.03 \\
$\mathrm{mrmr}$ & 0.08 & 0.08 \\
$\mathrm{mmrr}$ & 0.08 & 0.08 \\
$\mathrm{rmrr}$ & 0.21 & 0.21 \\
$\mathrm{mrrm}$ & 0.04 & 0.04 \\
$\mathrm{mrrr}$ & 0.21 & 0.21 \\
$\mathrm{rrrr}$ & 0.26 & 0.26 \\
\hline
\end{tabular}

${ }^{a} P_{\mathrm{r}}=0.72$.

value obtained from the relative intensity of the $\mathrm{mmm}$ tetrad. The assignments presented in Table IV were obtained by matching the calculated relative intensities with the closest observed relative intensity.

It should be noted that the proportion of racemic $\operatorname{diad} P_{\mathrm{r}}$ is equal to 0.72 and identical to the value found through the aromatic $\mathrm{C}_{1}$ carbon analysis.

The assignments obtained are quite different from these observed by Inoue and Randall.

Also, the 0.72 value of $P_{\mathrm{r}}$ obtained in our study is quite different from the value of 0.43 obtained by Randall.

Further study will be required to derermine if

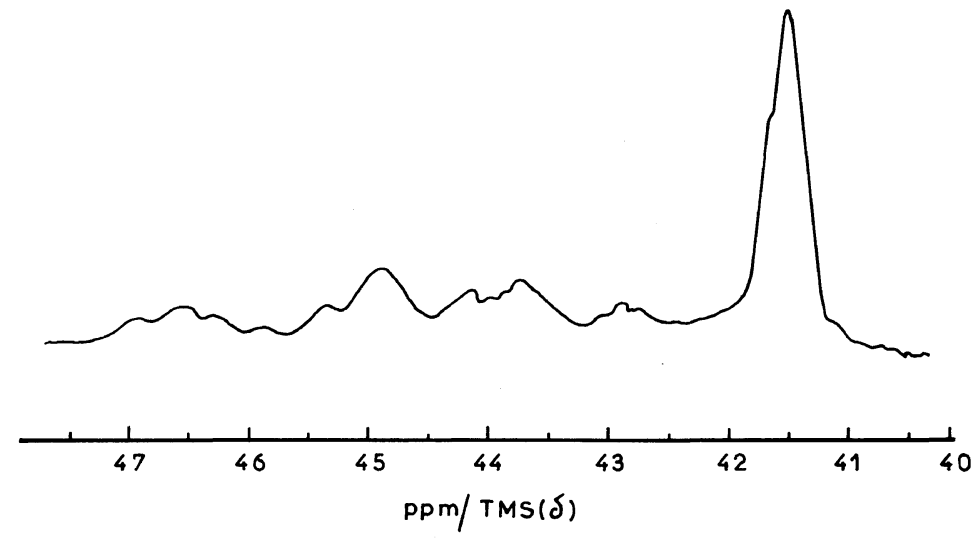

Figure 3. Observed ${ }^{13} \mathrm{C}$ NMR spectrum of the methylene carbon of a free-radical polystyrene. 
Table II. Observed and calculated peak proportions of the ${ }^{13} \mathrm{C}$ NMR spectra of the aromatic $\mathrm{C}_{1}$ carbon of a free-radical
polystrene (according to Inoue $)^{\mathbf{a}}$

\begin{tabular}{lcc}
\hline $\begin{array}{l}\text { Assignment } \\
\text { by pentads }\end{array}$ & Observed & $\begin{array}{c}\text { Calculated according } \\
\text { to a Bernoullian } \\
\text { statistics }\end{array}$ \\
\hline $\begin{array}{l}\text { mmmm } \\
\left.\begin{array}{l}\mathrm{mmmr} \\
\mathrm{rmmr}\end{array}\right\}\end{array}$ & 0.05 & 0.01 \\
$\left.\begin{array}{l}\mathrm{mmrm} \\
\mathrm{mrmr}\end{array}\right\}$ & 0.09 & 0.09 \\
$\left.\begin{array}{l}\mathrm{mmrr} \\
\mathrm{rmr}\end{array}\right\}$ & 0.09 & 0.13 \\
$\begin{array}{l}\mathrm{mrrm} \\
\mathrm{mrr}\end{array}$ & 0.19 & 0.29 \\
$\begin{array}{l}\mathrm{rrr} \\
\mathrm{mrr}\end{array}$ & 0.26 & 0.25 \\
\hline
\end{tabular}

a $P_{\mathrm{r}}=0.69$.

Table III. Observed and calculated peak proportions of the ${ }^{13} \mathrm{C}$ NMR spectra of the aromatic $\mathrm{C}_{1}$ carbon of a free-radical polystyrene (according to Matsuzaki) ${ }^{a}$

\begin{tabular}{|c|c|c|}
\hline $\begin{array}{l}\text { Assignment } \\
\text { by pentads }\end{array}$ & Observed & $\begin{array}{c}\text { Calculated according } \\
\text { to a Bernoulian } \\
\text { statistics }\end{array}$ \\
\hline $\mathrm{mmmm}$ & 0.02 & 0.01 \\
\hline $\left.\begin{array}{l}\mathrm{mmmr} \\
\mathrm{mmrm}\end{array}\right\}$ & 0.07 & 0.07 \\
\hline $\mathrm{rmmr}$ & 0.03 & 0.04 \\
\hline $\left.\begin{array}{l}\mathrm{mrmr} \\
\mathrm{mmrr}\end{array}\right\}$ & 0.18 & 0.17 \\
\hline mrrm & 0.02 & 0.04 \\
\hline $\left.\begin{array}{l}\mathrm{rmrr} \\
\mathrm{mrrr}\end{array}\right\}$ & 0.47 & 0.42 \\
\hline rrrr & 0.21 & 0.25 \\
\hline
\end{tabular}

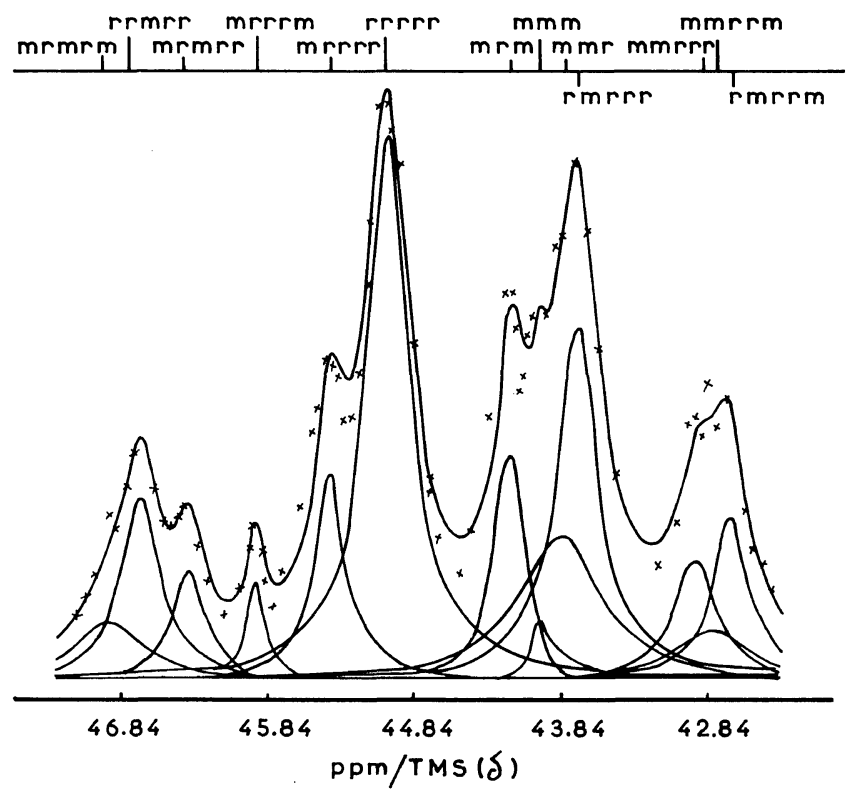

Figure 4. Composite ${ }^{13} \mathrm{C}$ NMR spectrum of the methylene carbon of a free-radical polystyrene. 
Table IV. Observed and calculated peak proportions of the ${ }^{13} \mathrm{C}$ NMR spectra of the methylene carbon of a free-radical polystrene (our results) $^{\mathbf{a}}$

\begin{tabular}{|c|c|c|}
\hline $\begin{array}{l}\text { Assignment } \\
\text { by hexads }\end{array}$ & Observed & $\begin{array}{c}\text { Calculated according } \\
\text { to a Bernoullian } \\
\text { statistics }\end{array}$ \\
\hline $\left.\begin{array}{l}\text { mrmrm } \\
\text { rrmrr } \\
\text { mrmrr }\end{array}\right\} r m r$ & 0.14 & 0.14 \\
\hline mrrm ) & 0.02 & 0.03 \\
\hline $\left.\left.\begin{array}{l}\text { mrrrr } \\
\text { rrrrr }\end{array}\right\} \operatorname{rrr}\right\}$ & 0.33 & 0.34 \\
\hline $\mathrm{mrm}$ & 0.07 & 0.06 \\
\hline $\begin{array}{l}\mathrm{mmm} \\
\mathrm{mmr}\end{array}$ & $\begin{array}{l}0.01 \\
0.12\end{array}$ & $\begin{array}{l}0.02 \\
0.11\end{array}$ \\
\hline $\left.\left.\begin{array}{l}\mathrm{rmrrr} \\
\mathrm{mmrrr} \\
\mathrm{mmrrm} \\
\mathrm{rmrrm}\end{array}\right\} \mathrm{mrr}\right\}$ & $\begin{array}{l}0.16 \\
0.15\end{array}$ & $\begin{array}{l}0.15 \\
0.14\end{array}$ \\
\hline
\end{tabular}

a $P_{\mathrm{r}}=0.72$.

statistical arguments should be used as the sole basis for configurational assignments.

\section{REFERENCES}

1. J. C. Randall, J. Polym. Sci., Polym. Phys. Ed., 12, 703 (1974).

2. A. Zambelli, D. E. Dorman, A. I. Richard Brenster, and F. A. Bovey, Macromolecules, 6, 925 (1973).

3. Y. Inoue, A. Nishioka, and R. Chûjô, Makromol. Chem., 152, 15 (1972).

4. W. D. Crain, Jr., A. Zambelli, and J. D. Roberts, Macromolecules, 3, 330 (1970).

5. C. J. Carman, Macromolecules, 6, 725 (1973).

6. C. J. Carman, A. R. Tarpley, Jr., and J. H. Goldstein, Macromolecules, 4, 445 (1971).

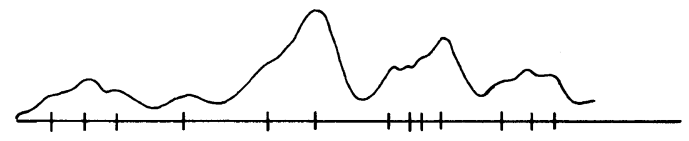

INOUE ASSIGNMENT.

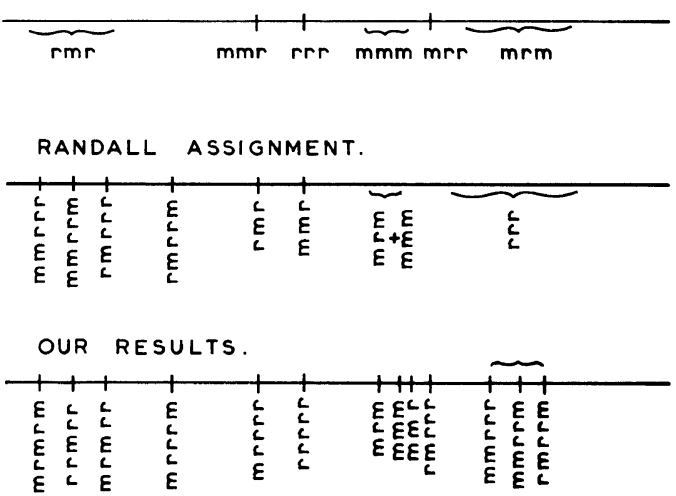

Figure 5. Chemical shifts of the methylene carbon according to Randall and Inoue.

7. T. K. Wu and D. W. Overnall, Macromolecules, 6, 582 (1973).

8. L. F. Johnson, F. Heatley, and F. A. Bovey, Macromolecules, 3, 175 (1970).

9. K. Matsuzaki, T. Uryu, K. Osada, and T. Kawamura, Macromolecules, 5, 816 (1972).

10. Y. Inoue, A. Nishioka, and R. Chûjô, Makromol. Chem., 156, 207 (1972).

11. K. Matsuzaki, T. Uryu, T. Seki, K. Osada, and T. Kawamura, Makromol. Chem., 176, 3051 (1975).

12. J. C. Randall, J. Polym. Sci., Polym. Chem. Ed., 13, 889 (1975).

13. T. Uryu, T. Seki, T. Kawamura, A. Funamoto, and K. Matsuzaki, J. Polym. Sci., Polym. Chem. Ed., 14, 3035 (1976).

14. T. Kawamura, T. Uryu, and K. Matsuzaki, Makromol. Chem., 180, 2001 (1979).

15. T. Uryu, T. Kawamura, and K. Matsuzaki, J. Polym. Sci., Polym. Chem. Ed., 17, 2019 (1979). 